\title{
WiRoTip: an IoT-based Wireless Sensor Network for Water Pipeline Monitoring
}

\author{
Fatma Karray $^{1,2}$, Mariem Triki ${ }^{2}$, Mohamed Wassim Jmal ${ }^{1,2}$, Mohamed Abid ${ }^{1,2}$, and Abdulfattah M. \\ Obeid $^{3}$ \\ ${ }^{1}$ Computer and Embedded System laboratory, National Engineering School of Sfax, University of Sfax, Sfax, Tunisia \\ ${ }^{2}$ Digital Research Center of Sfax, Technopole of Sfax, Sfax, Tunisia \\ ${ }^{3}$ National Center for Electronics and Photonics Technology, King Abdulaziz City for Science and Technology (KACST), \\ Riyadh, Saudi Arabia
}

\section{Article Info}

Article history:

Received October 31, 2017

Revised June 29, 2018

Accepted July 14, 2018

\section{Keyword:}

Wireless Sensor Network

Internet of Things

Node Design

Leak Detection

Water Pipeline Monitoring

ABSTRACT

One of the key components of the Internet of Things (IoT) is the Wireless Sensor Network (WSN). WSN is an effective and efficient technology. It consists of senor nodes; smart devices that allows data collection and pre-processing wirelessly from real world. However, issues related to power consumption and computational performance still persist in classical wireless nodes since power is not always available in application like pipeline monitoring. Moreover, they could not be usually suitable and adequate for this kind of application due to memory shortage and performance constraints. Designing new IoT WSN system that matches the application specific requirements is extremely important. In this paper, we present WiRoTip, a WSN node prototype for water pipeline application. An experimental and a comparative studies have been performed for the different node's components to achieve a final adequate design.
\end{abstract}

Copyright $(2018$ Institute of Advanced Engineering and Science. All rights reserved.

\section{Corresponding Author:}

Fatma Karray

Computer Science department

Sfax,Tunisia

$+21644295345$

karray.fatma.enis@gmail.com

\section{INTRODUCTION}

Internet of Things (IoT) allows us to transform the way of our perception and our interaction with the real world. It would make applications gain more efficiency, harness intelligence and get better accuracy by linking the physical objects to the information network. It offers also a promising solution of various existing industrial systems such as water transportation systems, manufacturing systems, etc [1].

Wireless Sensor Networks (WSNs) play a major role in this technology as intermediate to shape the physical world to human perception. Nowadays, WSN' applications are getting more and more attention from the industrial and the academic circles [2] [3] [4].

One of the most crucial application of WSN is water pipeline monitoring since worries about potable water have became more and more justified [5].

In that line, many studies have been made to propose solutions for leak detection and location in water pipeline. Most of them are focusing on the software aspect such as leak detection algorithms, communication protocols etc. Few others are targeting the hardware parts such as sensors, WSN platforms, etc [6]. However, the most common concern of WSN is power consumption since it determines the lifespan of the whole application.

The battery-powered sensors are responsible for gathering information and detecting leaks in order to react at the appropriate time. Therefore, in addition to energy preservation, enhancing the sensing capabilities by ameliorating the output signal of these sensors and treating their information is quite important when dealing with WSNs. 
IoT is not explored extensively in water pipeline monitoring. Few works exist for water management in general. For instance, the authors in [7] show the importance of IoT for water resource engineering. Some literature works are reported in this work. In [8], the authors describe the importance of IoT's usage for water management companies and the way of IoT integration for this management. Mohod [9] in the same way affirms the feasibility of IoT integration for Dam and Water Management. The authors in [10] present an IoT wireless sensor node for leak detection and water quality monitoring. The prototype consists of a microcontroller, a PH sensor, a vibration sensor, a flow sensor and a level sensor. Dhobale et al. [11] propose an IoT WSN system for water supply management. This system serves to automatically measure water level in dam and water flow rate. The sensor node is based on water flow sensor, Arduino board, ultrasound sensor and GSM module. The authors in [12] present a WSN prototype for waterwaste monitoring on IoT. The proposed design consists of a Wireless sensor node, a gateway node, a SMS-gateway and IoT Cloud platform. The authors describe The implementations of each part. The sensor node is composed of an Arduino Mega board, a wireless communication module, a sensor interface, a PH sensor, a conductivity sensor and a dissolved oxygen sensor. There is no power consumption or performance evaluation in the proposal. Nguyen et al. [13] describe an IoT WSN node for Environment monitoring. The node consists of nRF51822 System on Chip (SoC) that contains an ARM cortex M0 microcontroller and an energy harvesting module. Yang et al. [14] propose a WSN for water consumption monitoring at a household using IoT concept. However, these works are considered as attempts to use the IoT concept for water management systems and further improvements are needed especially in terms of performance and energy optimization.

The object of this work is to propose and evaluate WiRoTip, an IoT energy-efficient WSN prototype for leak detection in water pipelines. Moreover, we propose different circuits of signal conditioning as well as a hybrid leak detection algorithm based on kalman filter used in data processing.

This paper is organized as follows: In section 2, we present the WiRoTip. We introduce the proposed IoT architecture of the system, the software algorithm and the node design. We draw the experimental results in section 3 to finally finish with a conclusion and further future work in section 4.

\section{WIROTIP SYSTEM DESIGN}

In this section, we will detail our proposed solution. The architecture of IoT system will be presented. Software and hardware implementations of the sensor node will be described.

\subsection{IoT structure of the proposed system}

The WiRoTip system is designed for pressurized pipes. The proposed IoT architecture consists of multi-layers that interact and cooperate to detect and to locate leaks in water pipelines. Figure 1 shows the components of different layers.

The First layer is WSN layer in which the data is collected and pre-processed locally (not in the server). In fact, a pre-processing in node could save energy dissipated in frequent data transmission or sending useless information. Hence, a hybrid leak detection method based on Kalman filter (HLDKF) is implemented to detect leaks in water pipes. The sensor node in our case allows different tasks like data filtering, data processing, data compressing, data fusion, data aggregation, etc. After software implementation, a hardware experimental study is performed to select and design the different components of the node in subsection 2.3.

The second layer is the networking, the service and the storage layer. In this layer, the communication between nodes, gateways and the base station is performed. The sensors are fixed in sleep mode and get data every 8 hours. The HLDF is run to filter data and to test leak occurrence. When a leak occurs, the data is collected with a high sampling rate. The compressed data and leak information are firstly forwarded from nodes to cluster heads, in which the leak position is calculated, and then to the cloud.

The final layer is the application layer in which the user could interact with the sensors' information. In this step, various analyses are performed and visualized online. An interactive user interface is developed to access the pipelines information. In the application, users are allowed to access to leaks information, statistics, graphs, pipeline state and network information.

\subsection{WiRoTip Leak detection and data filtering module}

Kalman filter (KF) [15] is an efficient predictive and estimator. The usage of such algorithm jointly with WSN has not been explored yet for water pipeline application to the best of our knowledge. However, some papers have used KF for leak detection. For example, Benkherouf in 1988 proposes an Extended KF 


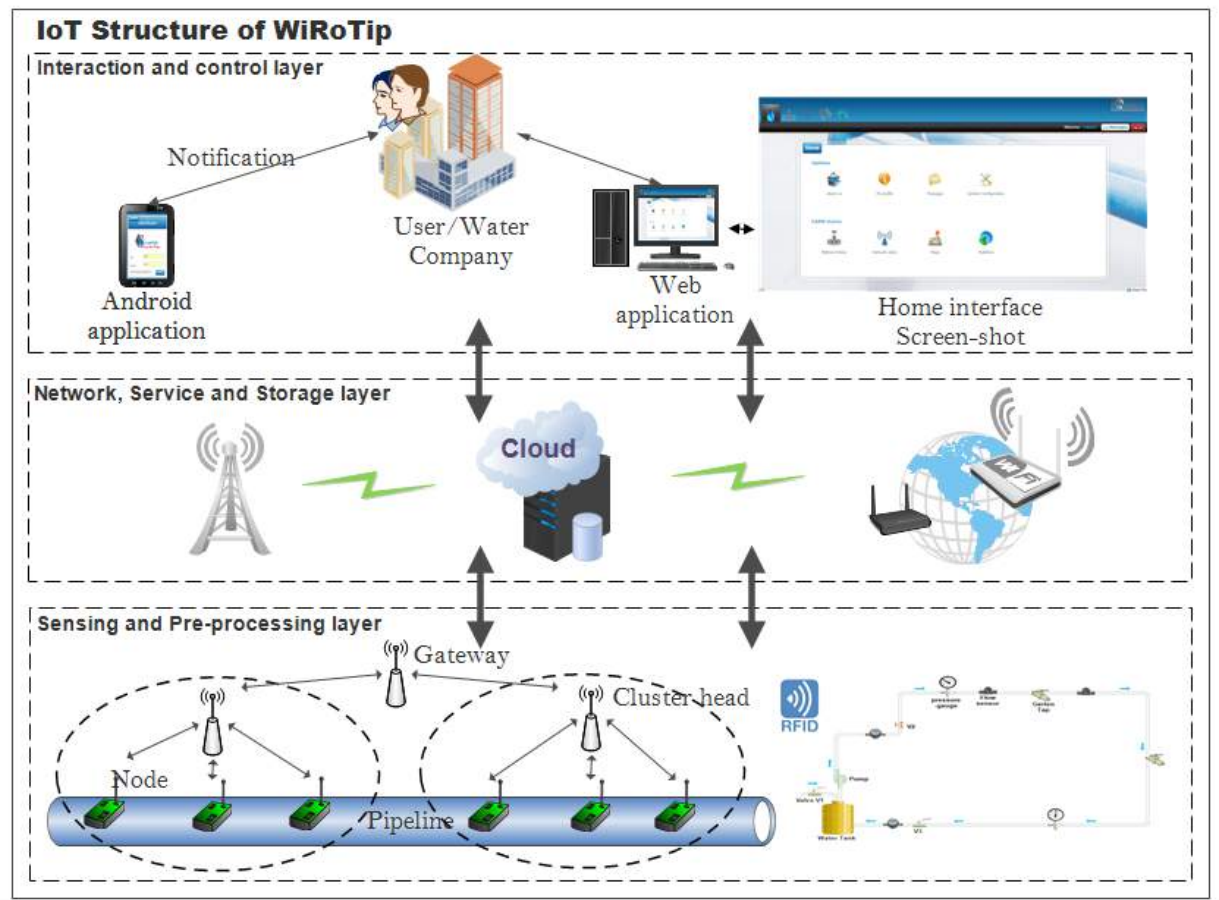

Figure 1. WiRoTip IoT architecture

$(\mathrm{EKF})$ in the context of pipeline monitoring [16]. The authors in [17] suggest a linear KF for leak detection based on pressure and flow measurements. They suppose that in a given time step, the measurement state is similar with the one of previous week. Jung et al [18] propose a leak detection method based on a statistical process control and a KF to detect bursts in pipelines. However, these works do not explore the KF in the context of WSN-WPM application.

We implement a HLDKF to perform data filtering and leak detection in water pipes. Figure ?? shows The flowchart of the algorithm. KF is a recursive data processing algorithm for dynamic systems. It employs a set of mathematical equations to produce an optimal estimation of the system [19]. This algorithm with be used in the next section for evaluating the performance of the processing module.

\subsection{WiRoTip Node design}

To design an energy-efficient node and to perform a good choice of the node components, a theoretical and experimental study about the node components is necessary. A typical sensor node consists of four modules [20]:

- The processing unit: For the processing unit, we have used an Arduino Uno [21]. This platform is open hard and facilitated hardware understanding. It allows also easy integration of sensors and communication devices (transceivers).

- The communication unit: This unit is composed of a transceiver that transmits and receives data wirelessly. A nRF24101 is used for this unit as shown in Figure 2. The nRF24101 [22] is a $2.4 \mathrm{GHz}$ Radio Transceiver. The choice of this transceiver is due to its low power, its low cost and its compatibility with Arduino board, yet, for final prototype or product, nRF24L01+ or the SoCs nRF24LE1 or nRF24LU1+ are more suitable [22].

For the gateway, we have used the Ethernet communication. Ethernet (also known as the IEEE 802.3 standard) [23] is a standard for data transmission for local area network. We have used for our prototypes Arduino Ethernet Shield V1 [24] to connect the Arduino to the internet (gateway) as shown in Figure 2. The acquisition of Wifi shield was not possible. That is why, we have used Ethernet shield.

- The sensing unit: This unit is in charge of gathering data from physical environment. This part is very crucial as the accuracy of any sensor will affect the all system (to design sturdy system). Pressure and 


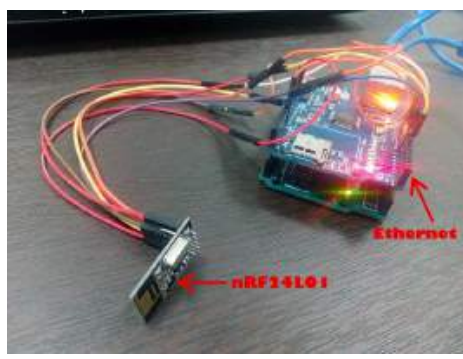

Figure 2. Ethernet Transceiver connected to Arduino Uno board

Flow sensors are used as inputs of the HLDKF as detailed below:

1. YF-S201 Hall Effect Water Flow Sensor: This sensor is used to measure the flow variations in water pipes [25]. It is a destructive sensor aligned with the water pipe. The accuracy of this sensor is about $+/-10 \%$ and the flow rate varies from 1 to 30 liters per minute. This sensor is widely employed due to its pulse-based mechanism that allows low power consumption. Figure 3 shows the way in which this sensor is attached to the pipe and to the sensor node.

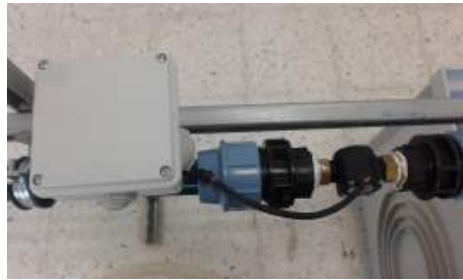

Figure 3. YF-S201 Hall Effect Water Flow Sensor attached to our demonstrator and to the sensor node

2. Force Sensitive Resistor (FSR) sensor: FSR is an analog sensor used to measure pressure in water pipes. It is a polymer thick film device characterized by its easy-to-use and low cost [26]. Figure 4 illustrates the different parts of the sensor. When a force/pressure is exercised to the sensor, the resistor element is deformed and the air is pushed from the spacer. The accuracy of sensor is $+/-$ $10 \%$.
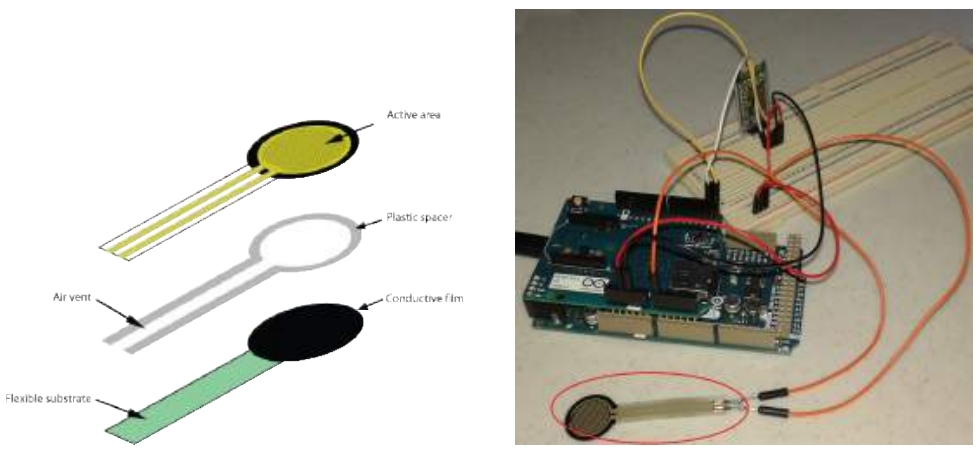

Figure 4. FSR sensor

In our case, the sensor is attached to the outside of the pipeline and fixed with a join. The pipeline pressure produces a contact force between the pipe and the join. When a leak occurs, it causes pressure variations which affect the contact force.

- The power management unit manages and provides energy to the all sensor node components. In this paper, we have not worked on this unit. However, some energy optimization techniques are used to save the all power of the node.

This study is very important to master the hardware part and select the best components of the IoT node. 


\section{RESULTS AND ANALYSIS}

The WiRoTip prototype is tested using a demonstrator installed in our research center [27]. Figure 5 shows an almost rectangular section composed of $25 \mathrm{~m}$ polyethylene pipes. These pipes have $32 \mathrm{~mm}$ as an

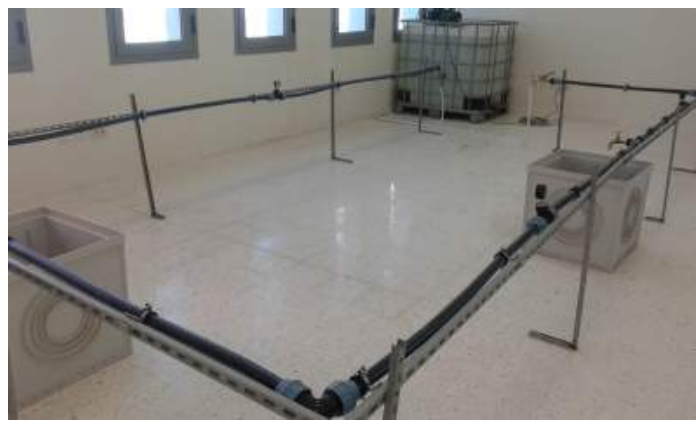

Figure 5. WiRoTip Testbed

external diameter. They support up to 12 bar of pressure. The choice of this sort of pipes is thanks to their low cost, their resistance and insensitivity to chemical and electrical corrosion. Furthermore, they are used in the real distribution systems of our country. More general, the use of plastic pipes has increasingly widespread all over the world.

The setup consists also of two valves in inlet and outlet points in order to vary the users demands by varying the pressure. A $1000 \mathrm{~m}^{3}$ reservoir is used as a water source. To control the inlet and outlet water, we employ two flow meters. As the pipes are made at the same level, the water is moving along the pipes by an electrical pump with $1 \mathrm{hp}$ motor providing up to 4 bar when the output valve is closed and up to 2.5 bar in open circuit. The supports are designed to have variable heights that we will explore in the future to see the effect of this variation on the pressure and to test our algorithm in varied conditions. Finally, The leaks are induced using two garden taps.

This demonstrator is used to test the proposed sensor node. The prototype is made up of the Arduino board, the nRF24101 transceiver, the flow sensor and the relay. Table 1 illustrates also the power consumption distribution of the node prototype. In this table, each of the node components is shut down to see it effect in the whole power of the node.

Table 1. Power distribution in the Arduino-nRF24101 prototype

\begin{tabular}{|c|c|c|c|c|c|c|}
\hline Arduino & Relay & $\begin{array}{c}\text { Flow } \\
\text { sensor }\end{array}$ & algorithm & nRF24101 & $\begin{array}{c}\text { Current } \\
(\mathrm{mA})\end{array}$ & $\begin{array}{c}\text { Power } \\
(\mathrm{mW})\end{array}$ \\
\hline on & on & on & HLDKF & $\begin{array}{c}\text { Tx } \\
(11 \mathrm{~mA})\end{array}$ & 85.47 & 396.3 \\
\hline on & on & on & HLDKF & $\begin{array}{c}\mathrm{Rx} \\
(18 \mathrm{~mA})\end{array}$ & 92.47 & 419.4 \\
\hline on & on & Off & HLDKF & $\begin{array}{c}\text { Idle } \\
(2 \mathrm{~mA})\end{array}$ & 34 & 381.5 \\
\hline on & off & off & HLDKF & off & 32 & 160 \\
\hline $\begin{array}{c}\text { sleep } \\
(\text { PWR_DOWN })\end{array}$ & off & off & HLDKF & off & 26 & 130 \\
\hline
\end{tabular}

Table 2 illustrates the power consumption of the sensors used for WiRoTip. These sensors are low power and they kept shut down as longer as possible to save the power of the node.

Table 3 represents the power distribution analysis of the gateway prototype which is based on Ethernet shield V1. We note that the Ethernet module has high power consumption. However, it is used due to material constraints.

Figure 6 summarize the power profiles of WiRoTip node and Gateway.

We remember that this proposal is a prototype for more energy saving a PCB board needs to be designed. Moreover, due to the lack of information of power consumption in the other approaches, we implement our algorithm in two other sensor nodes: Arduino Due and MKR1000 to compare our work with others as repre- 
Table 2. Experimental Power Consumption of each Sensor

\begin{tabular}{|c|c|c|c|}
\hline Sensor & $\begin{array}{c}\text { Voltage } \\
(\mathbf{V})\end{array}$ & $\begin{array}{c}\text { Current } \\
(\mathbf{m A})\end{array}$ & $\begin{array}{c}\text { Power } \\
(\mathbf{m W})\end{array}$ \\
\hline $\begin{array}{c}\text { YF-S201 } \\
\text { sensor }\end{array}$ & 5 & 2.47 & 12.35 \\
\hline FSR & 5 & 2.3 & 11.5 \\
\hline
\end{tabular}

Table 3. Power distribution in the Arduino-Ethernet prototype

\begin{tabular}{|c|c|c|c|c|}
\hline Arduino & Relay & $\begin{array}{c}\text { Ethernet } \\
\text { mode }\end{array}$ & $\begin{array}{c}\text { Current } \\
(\mathrm{mA})\end{array}$ & $\begin{array}{c}\text { Power } \\
(\mathrm{mW})\end{array}$ \\
\hline on & on & $\begin{array}{c}\mathrm{Tx} \\
(167 \mathrm{~mA})\end{array}$ & 239 & 1195 \\
\hline on & on & $\begin{array}{c}\mathrm{Rx} \\
(160 \mathrm{~mA})\end{array}$ & 232 & 1160 \\
\hline on & on & $\begin{array}{c}\text { Idle } \\
(150 \mathrm{~mA})\end{array}$ & 222 & 1110 \\
\hline
\end{tabular}

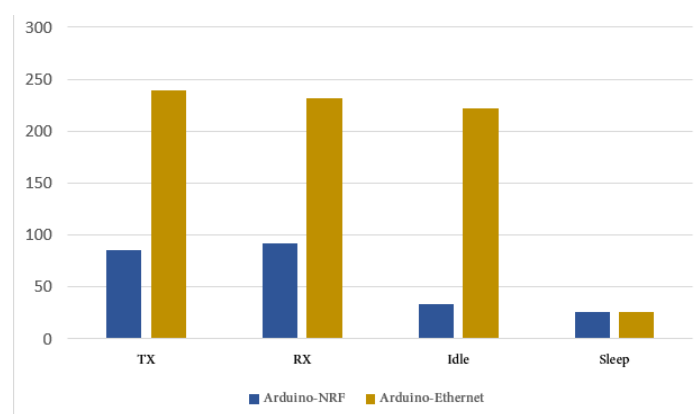

Figure 6. WiRoTip Power Consumption Summary

sented in Table 4. As we can see, in the Table 4, our proposal still have the lowest power consumption while improvements still needed in this respect.

Table 4. Comparison of WiRoTip with other Approaches

\begin{tabular}{|c|c|c|}
\cline { 2 - 3 } \multicolumn{1}{c|}{} & Time $(\mu \mathrm{s})$ & Power $(\mathrm{mW})$ \\
\hline WiRoTip & 80 & 187.5 \\
\hline Arduino Due & 30 & 557 \\
\hline MKR1000 & 40 & 600.5 \\
\hline
\end{tabular}

\section{CONCLUSION}

In this paper, we develop an IoT WSN node prototype for water pipeline monitoring application. Various tests and implementations have been performed for different units to design an energy aware reliable system. The sensing unit was a crucial unit. In fact, calibrations and amplifier have been added to adjust the signal coming from polyethylene pipes. Communication and power management techniques have been also evaluated. All this work has permit us to design and evaluate WiRoTip node.

As future work, a PCB board will be developed to get our own ultra low power product with sensor board extension. Tests and experiments will be performed not only in the demonstrator but also in real field. 


\section{ACKNOWLEDGMENT}

The authors would like to thank the King Abdulaziz City for Science and Technology (KACST) which supports this work under a research grant (project no. 35/1012).

\section{REFERENCES}

[1] A. Rghioui and A. Oumnad, "Internet of things: Surveys for measuring human activities from everywhere," International Journal of Electrical and Computer Engineering (IJECE), vol. 7, no. 5, p. 2474, 2017.

[2] C.-Y. Chong and S. P. Kumar, "Sensor networks: evolution, opportunities, and challenges," Proceedings of the IEEE, vol. 91, no. 8, pp. 1247-1256, 2003.

[3] A. A. Jaber and R. Bicker, "Design of a wireless sensor node for vibration monitoring of industrial machinery," International Journal of Electrical and Computer Engineering, vol. 6, no. 2, p. 639, 2016.

[4] H. Sayuti, R. Rashid, N. A. Latiff, M. A. Rahim, A. Abdul, M. Sarijari, and N. Ghazali, "Smart home and ambient assisted living based on the internet of things," International Journal of Electrical and Computer Engineering, vol. 7, no. 3, p. 1480, 2017.

[5] M. M. Mekonnen and A. Y. Hoekstra, "Four billion people facing severe water scarcity," Science advances, vol. 2, no. 2, p. e1500323, 2016.

[6] F. Karray, A. Garcia-Ortiz, M. W. Jmal, A. M. Obeid, and M. Abid, "Earnpipe: A testbed for smart water pipeline monitoring using wireless sensor network,” Procedia Computer Science, vol. 96, pp. 285-294, 2016.

[7] S. Deshmukh and P. Barapatr, "Internet of things based system for water resource engineering," in Emanations in Modern Technology and Engineering (ICEMTE), 2017 International Conference on, vol. 5. IEEE, 2017, pp. 240-242.

[8] T. Robles, R. Alcarria, D. M. de Andrés, M. Navarro, R. Calero, S. Iglesias, and M. López, "An iot based reference architecture for smart water management processes," JoWUA, vol. 6, no. 1, pp. 4-23, 2015.

[9] N. Mohod, "Usability of internet of things [iot] for dam safety and water management," International Journal of Research in Advent Technology, vol. 5, no. 1, pp. 29-30, 2017.

[10] S. Ezhilvanji and S. Malarkodi, "An efficient water distribution system for india using iot," International Innovative Research Journal of Engineering and Technology, 2017.

[11] G. S. P. G. P. J. H. K. A. Dhobale, Kiran M. and U. A. Mande, "Iot based smart water supply management system," Advanced Research in Computer and Communication Engineering, vol. 6, no. 3, 2017.

[12] Y. Zakaria and K. Michael, "An integrated cloud-based wireless sensor network for monitoring industrial wastewater discharged into water sources," Wireless Sensor Network, vol. 9, no. 08, p. 290, 2017.

[13] C. M. Nguyen, J. Mays, D. Plesa, S. Rao, M. Nguyen, and J.-C. Chiao, "Wireless sensor nodes for environmental monitoring in internet of things," in Microwave Symposium (IMS), 2015 IEEE MTT-S International. IEEE, 2015, pp. 1-4.

[14] S.-H. Yang, X. Chen, X. Chen, L. Yang, B. Chao, and J. Cao, "A case study of internet of things: A wireless household water consumption monitoring system," in Internet of Things (WF-IoT), 2015 IEEE 2nd World Forum on. IEEE, 2015, pp. 681-686.

[15] H. Alrawashdeh and J. A. Sumadu, "The kalman filter performance for dynamic change in system parameters," International Journal of Electrical and Computer Engineering (IJECE), vol. 3, no. 6, pp. 713-723, 2013. [Online]. Available: http://iaesjournal.com/online/index.php/IJECE/article/view/3857

[16] A. Benkherouf and A. Allidina, "Leak detection and location in gas pipelines," in IEE Proceedings D (Control Theory and Applications), vol. 135. IET, 1988, pp. 142-148.

[17] G. Ye and R. A. Fenner, "Kalman filtering of hydraulic measurements for burst detection in water distribution systems," Journal of pipeline systems engineering and practice, vol. 2, no. 1, pp. 14-22, 2010.

[18] D. Jung and K. Lansey, "Water distribution system burst detection using a nonlinear kalman filter," Journal of Water Resources Planning and Management, vol. 141, no. 5, p. $04014070,2014$.

[19] R. E. Kalman, "A new approach to linear filtering and prediction problems," Journal of basic Engineering, vol. 82, no. 1, pp. 35-45, 1960.

[20] F. Karray, W. M. Jmal, M. Abid, D. Houssaini, A. M. Obeid, S. M. Qasim, and M. S. BenSaleh, "Architecture of wireless sensor nodes for water monitoring applications: From microcontroller-based system to soc solutions," in Environmental Instrumentation and Measurements (IMEKO), 2014 5th IMEKO TC19 Symposium on, 2014, pp. 20-24.

[21] Arduino. Arduino/genuino uno description. [Online]. Available: 
https://www.arduino.cc/en/Main/ArduinoBoardUno

[22] nRF24L01 Single Chip 2.4GHz Transceiver Product Specification, Nordic semiconductor, Jul. 2007.

[23] Z. Lin and S. Pearson, "An inside look at industrial ethernet communication protocols," Texas Instruments, White Paper, 2013.

[24] Arduino. Arduino ethernet shield

v1. [Online].

Available: https://www.arduino.cc/en/Main/ArduinoEthernetShieldV1

[25] Data-sheet,Prodcut Introduction, YIFA the plastics Ltd.

[26] F. S. R. A. O. of the Technology, "Data-sheet," Interlink Electronics.

[27] Digital research centre of sfax. [Online]. Available: http://www.crns.rnrt.tn/ 


\section{BIOGRAPHIES OF AUTHORS}
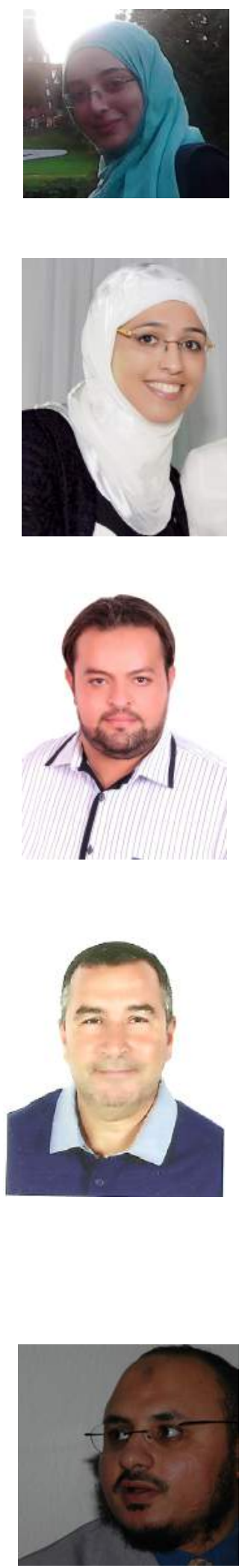

Fatma Karray is a Phd student at the Computer and Embedded Systems (CES) laboratory and at the Digital Research Center of Sfax, Tunisia (2014). She has received the Engineering degree in embedded systems from the National School of Engineer of Sfax, Tunisia in 2013. Her current research interests are in the fields of embedded systems, Wireless Sensor Networks, Signal processing, IoT applications, Smart Infrastructures monitoring, System on Chip design and Low power design. Fatma Karray serves as a reviewer in international journals and conferences and as organizer in national events and workshops.

Mariam Triki Electrical engineer from the national school of engineering of Sfax , Tunisia (2016). She specialized in electronics and new technologies. She worked as an RD engineer at the Computer and Embedded Systems Laboratory (CES labs) and at the Digital Research Center of Sfax. She is passionate about IoTs, sensors, analog systems and electronic devices.

Mohamed Wassim Jmal is an Associate Professor at the Higher Institute of Applied Sciences and Tecnology of Gafsa, Tunisia since 2012. His research activity is conducted within CES Laboratory. He has received the Engineering degree in Electrical Engineering, from the National Engineering School of Sfax in 2005 and the Master degree in Automatic and Industrial Informatics, from the same Engineering School, in 2007. He got the PhD in Electrical Engineering in 2013. His current research interests are in the field of Wireless Sensor Networks (WSN) and the Embedded Systems. They are focused on the implementation of wireless sensor networks applications in Reconfigurable System. He has several publications in many conferences and Journals. Mohamed Wassim JMAL served in national and international conference organization: IDT, ICM, TWESD, SensorNets.

Mohamed Abid is Head of "Computer Embedded System" laboratory CES-ENIS, Tunisia. He is working now as a Professor at the Engineering National School of Sfax (ENIS), University of Sfax, Tunisia. He received the $\mathrm{PhD}$ degree from the National Institute of Applied Sciences, Toulouse (France) in 1989 and the "thse d'tat" degree from the National School of Engineering of Tunis (Tunisia) in 2000 in the area of Computer Engineering and Microelectronics. His current research interests include hardware/software co-design, System on Chip, Reconfigurable System, and Embedded System, biometric, etc. He has also investigated the design and implementation issues of FPGA embedded systems. Dr. Abid is joint coordinator or an active member of several International Research and Innovation projects. He was Supervisor or Co-supervisor of more than $50 \mathrm{PhD}$ doctors. He is author or co-author of more than 150 publications in Journals and of more than 300 papers in international conferences. He is also author or co- author of many guest's papers, Joint author of many book's chapters. Dr. Abid has served also as Guest professor at several international universities and as a Consultant to research and development in Telnet Incorporation.

Abdulfattah M. Obeid is currently general manager at Saudi Technology Development and Investment Company (TAQNIA)and associated professor at National Center for Electronics and Photonics Technology, King Abdulaziz City for Science and Technology (KACST), Riyadh, Saudi Arabia. He has received the Bachelor of Science (BSc) Electrical, Electronics and Communications Engineering in King Saud University in 1994, the Master degree of Electrical Engineering in Michigan State University, East Lansing, MI, USA in 1999 and the PhD degree in Electrical Engineering and Information Technology, TU-Darmstadt, Darmstadt, Germany in 2006. His current research interests are in the fields of embedded systems, Wireless Sensor Networks, System on Chip design and Low power design. Obeid serves as a reviewer in international journals and conferences and as organizer in international conferences and workshops. 